\title{
The Effect of Health Community Behavior (PHBS), Health Service Quality to Diare's Disease in Sub-Division Karang Jaya Palembang Sub-District
}

\author{
Iman Suwono ${ }^{1}$, M.T. Kamaluddin ${ }^{2}$, Sriati ${ }^{3}$, Dwi Putro Priadi ${ }^{4}$ \\ ${ }^{1}$ Doctoral Program of Environmental Science, Sriwijaya University, Indonesia \\ ${ }^{2}$ Faculty of Medicine, Sriwijaya University, Indonesia \\ ${ }^{3}$ Faculty of Agriculture, Sriwijaya University, Indonesia \\ ${ }^{4}$ Faculty of Agriculture, Sriwijaya University, Indonesia
}

\begin{abstract}
The aims of this study were to analyze the Effect of Healthy Living Community Behavior (PHBS), Quality of Health Service against Overcoming Diarrhea Disease in Sub-division Karang Jaya Palembang. The type of research used in this study was analytical research. This research was conducted in Palembang City selected area of Karang Jaya Sub-district Gandus District. The study was conducted in May 2016 to June 2017. The samples of research were people affected by diarrhea in 2017 as many as 95 people. Method's of data analysis using logistic regression. Result showed that the PHBS coefficient with odds ratio-0.760 (1.561-0.370) with significance of 0.045 less than the 0.05 significance level $(\alpha)$. This means that hypothesis one $(\mathrm{H} 1)$ was accepted if the variable quality of health service, constant then every increase PHBS effect on the occurrence of diarrhea. The better PHBS will decrease the incidences of diarrhea. Coefficient of health service quality with odds ratio $1.598(3.217-0.74)$ with significant equal to 0.009 less than level of significant $(\alpha) 0.05$. This means that hypothesis two (H2) is accepted if the variable PHBS, constant then the quality of health services affect the occurrence of diarrhea. The better quality of health care will reduce the incidence of diarrhea
\end{abstract}

Keywords: PHBS, quality of service, health, diarrhea

\section{Introduction}

Health is a human right and one of the elements of welfare that must be realized in accordance with the ideals of the Indonesian nation as intended in the Preamble of the Constitution of the Republic of Indonesia Year 1945. Improvement of optimal health status for the community is conducted through health efforts with maintenance approach, health (promotive), prevention of disease (preventive), curative disease (curative) and health recovery (rehabilitative) is done thoroughly, integrated and sustainable. Implementation of health service efforts is implemented by health personnel who have the authority and minimum qualifications.

Indonesia's health development aims to encourage people to live healthy lives. Healthy living behaviors can be enhanced through various extension and health education activities to become part of the community's living and cultural norms. One of the Department of Health's main strategies is to mobilize and empower people to live healthy lives (Hapsara, 2004). The health rating in Indonesia for the past three decades has increased significantly, but when compared to neighboring countries, the increase is still low. The main problem faced is the low quality of public health seen in $\mathrm{MOH}$ strategy plan. (2005), Maternal Mortality Rate (MMR): 262/100,000 live births and Life expectancy (UHH): 69 years (Ministry of Health RI, 2005).

The strategy to achieve the vision of Healthy Indonesia 2010 is

Article History:

Received: 12 November 2017

Accepteed: 20 February 2018

DOI: $10.22135 /$ sje.2018.3.1.19-26

*Corresponding Author: panther_aldo@yahoo.com to increase public access to quality health services with the main objectives of each village in the availability of competent human resources (HR) and health services in every Hospital, Center for Public Health, and its network meet the quality standard (Fahriadi, 2006). The community is entitled to health services with the best performance of health promotion staff and other health workers. However, affordable and quality health services are still difficult to implement. Not infrequently heard about the poor practice of health care services provided to the community both in hospitals, health centers, as well as health care clinics.

The facts in Indonesia, including the service of Center for Public Health and hospitals, indicate that there are still many complaints and dissatisfaction with the quality of service of the government apparatus in spelling out its public service duties, especially when it is associated with the obligation to observe the principles of good governance. Not infrequently, the low quality of public services is the cause of cases that can be categorized as mal-administration, such as protracted service, unfair treatment, demand for compensation, and abuse of authority (Riyadi, 2005: 23).

In general the above conditions stems from the poor three aspects of the pattern of implementation (management), human resources and public service institutions in Indonesia covering (Syukri, 2007):

1. The pattern of organizing is less responsive, less informative, less accessible, less coordinated, too bureaucratic, unwilling to listen, and inefficient;

2. Human resources are less professional, competent, empathy, and ethical;

3. Institutions tend to be hierarchical and not designed to be able to provide services to the community efficiently and optimally.

Some Health Center and hospitals have a number of patient visits and the number of different employees. In improving the quality of public services, the government makes a policy by applying quality management of international standard services in the hope 
of improving the quality of public services, especially in the health sector. Because Center for Public Health is a government-owned agency that serves the community and its presence is close to the middle and lower class society.

This is important as a reference in improving services in order to provide optimal satisfaction. The main problem as a health service institution that many competitors are the services provided whether it is in accordance expectations of patients/consumers or not so that community satisfaction about health services will be achieved so that people avoid infectious diseases such as diarrhea.

There are many factors that cause diarrhea due to the low healthy lifestyle of the community, especially the provision of good sanitation facilities to support environmental health. Because until now, it is estimated that about $47 \%$ of Indonesian people still defecate carelessly, there are those who defecate to rivers, gardens, rice fields, ponds and other four open places. Such behavior is clearly very detrimental to public health conditions, because the stool is known as a medium where e.coli bacteria that potentially cause diarrheal disease live. In accordance with research Kusumaningrum, et al (2011) there is a significant relationship between the use of latrines and the incidence of diarrhea of under-five year in Sub-division Gandus Palembang.

Based on cases of diarrhea that occurred in the city of Palembang caused by the condition of environmental sanitation is still bad. Palembang city also experienced the process of dynamics and the flow of urbanization with various interests that impact on population growth. Currently, the population growth of Palembang City reaches $2.65 \%$. This relatively high rate of population growth if not matched by the availability of basic urban infrastructure will create complicated problems for the government. One of the problems faced by the city of Palembang is the emergence of slums (slums area), especially along the Musi River.

The high incidence of diarrhea in the Karang Jaya sub-division area is one of the causes Behavior and Habit on average do not wash hands with soap after defecation, there are 10 families do not have latrines and do defecate in the river, the condition of the toilet is not clean, to septic tank with a swan neck. The people of sub-division Karang Jaya generally use clean water source from the Drinking Water Company (PAM), there is also using well water. Waste management using a system burned after a few days previously dumped in the back of the house; do not think about the development of settlements. The pattern of serving the community usually does not cover the food stored so easily visited by flies. When preparing food, people pay less attention to the cleanliness of foodstuffs and cooking supplies

Implementation of environmental-based sanitation in the prevention of diarrheal diseases has led to public satisfaction with the sanitation program and the prevention of diarrheal diseases. The level of community satisfaction with the environment-based sanitation program and the prevention of diarrhea by the government is still quite low as evidenced by some empirical research on the quality of environmental-based sanitation and the prevention of diarrhea. There are several factors related to the implementation of total sanitation based PHBS programs with diarrhea events such as demographic conditions, behavior and community satisfaction. The results of research on the analysis of various factors that influence the implementation of clean and healthy life behavior, shows that there is a relationship between attitude variables and knowledge about PHBS household.

Based on these descriptions the authors are interested to conduct research on Environmental Factors and Behavior as an effort to improve the quality of community life related to public health integrated environmental health. PHBS is all health behavior that is done on the awareness so that family members or family can help themselves in the field of health and play an active role in activities in the community (MOH, 2007: 2). The purpose of this study was to analyze the Effect of Healthy Living Community Behavior (PHBS), Quality of Health Service against Overcoming Diarrhea Disease in sub-division Karang Jaya Palembang

\section{Literature Review}

\subsection{Quality of Health Services}

The realization of a healthy state is the desire of all parties not only by individuals, but also by their families, groups and even people. To be able to make it happen healthy things are many things that need to be done. One of them is considered to have a significant role is to provide health services (Azrul, 1996). Levey and Loomba (1973) Levey's health services is any effort that is self-administered or jointly within an organization to maintain and improve health, prevent and cure diseases and restore the health of individuals, families, groups and or society (Azrul 1996). In accordance with such limits it is immediately easy to understand that forms and types of health can be found in many ways. A health service is said to be good (Azrul, 1996) if the following conditions:

\section{Available and sustainable}

A good health service is a health service needed by the community is not hard to find, and its presence in the community is at any time needed.

2. Acceptable and reasonable

This means that health services are not contrary to the beliefs and beliefs of society.

3. Easy to reach

To be able to realize good health service then arrangement distribution of health facility become very important. Health services that are too concentrated in urban areas alone and while not found in rural areas, are not good health services.

4. Easy to reach

The affordability is from the point of cost.

5. Quality

That is indicating the level of perfection of health services held, which on one hand can satisfy the users of services, and on the other hand the procedures of implementation in accordance with codes of ethics and standards that have been set.

Elements forming hospital services are grouped into 4 (four) groups:

1. Input element

The input element is everything that is necessary for the implementation of hospital services. This group includes the building where the services are held, medical and non medical equipment, human resources and budget.

\section{Process Elements}

Process elements are all activities undertaken in the framework of service or any interaction that occurs between the resources of the hospital with the patient.

3. Out put elements

Element output is everything as a result of the process of organizing services in the hospital include among others, healing, death, disability, satisfaction and others.

4. Environmental elements 
The element of the environment is anything that is regulating or limiting activities in the hospital. The input elements, process elements, and environment with their respective components have interconnected characteristics, as well as mutual influence and all of which are factors that affect the quality of hospital services (Noor, 2001).

In addition, the implementation of excellent health services need to pay attention to the following matters (Wijono, 1999):

1. Seek clear exposure through information boards or easy-to-understand instructions and obtain at each place/location of service in accordance with its importance concerning procedures/ procedures of service, registration, sampling or inspection results, fees/tariffs/services and schedule.

2. Any rules on procedures/procedures/guidelines as mentioned above shall be executed appropriately, consistently and consistently in accordance with applicable laws and regulations.

3. The rights and obligations of the giver or recipient of service shall be clearly stipulated every requirement required in order to receive services shall be easily obtained and directly related to the interests of the service and shall not increase the burden of the recipient community.

4. Available information booths and suggestion boxes for recipients of services that are easy to see/be found at any place of service.

5. Handling the service process wherever possible by authorized or competent, capable, skilled and professional officers in accordance with the specifications of their duties.

6. Always strived to create appropriate service patterns in accordance with the nature and types of services concerned with considering the efficiency and effectiveness in the implementation.

6. The cost/tariff of service should be set fairly by taking into account the ability of the community. Should be strived to regulate the levy mechanisms that facilitate their payments and do not incur high costs.

7. Provision of services shall be conducted in an orderly, orderly and fair manner by not distinguishing the social status of the community.

8. The sanitation and sanitation of the premises of premises and service facilities should always be guaranteed through routine cleaning.

9. Always strived for officers to provide services with a friendly and polite attitude and strive to improve the performance of health services optimally.

10. Achievement of excellent service in health will always be monitored and evaluated regularly and periodically. Gradually excellent service should be implemented by all existing health service units (Wijono, 1999).

The excellent service indicators are as follows (Sampara, 2005):

1. Simplicity, in the sense that the procedure / procedure of service is carried out easily, smoothly, quickly, not convoluted, easy to understand and easy to do;

2. Clarity and certainty: the clarity of certainty about:

a. Procedures / procedures of public services

b. General service requirements, both technical and administrative

c. nit work and or officials authorized and responsible in providing public services d. Details of costs / tariffs of public services and procedures for payment

e. Scheduled time of public service completion

f. Hak and the obligations of both the grantor and the recipient of the public service based on the receipt of the application / completeness, as a means to ensure starting from the process of public service to the completion.

g. Officers who receive public complaints when there is something unclear and dissatisfied with the services provided to the public (customers).

3. Security, in the sense that the process and outcome of public services can provide security and convenience and can give general assurance

4. Disclosure, in the sense of procedure / procedure of requirement, work unit of responsible officer of public service, time of completion and detail of cost / tariff and other matters relating to process of public service must be informed open to be easily known and understood by society, either asked or did not ask.

5. Efficient, in the sense that the requirements of public services are limited to matters directly related to the achievement of service targets while maintaining the cohesiveness between the requirements and the products of public services provided.

6. Economical, in the sense that the costs to be paid by the community must remain reasonable

7. Equitable Justice

8. Timeliness of service

The Health Center is the spearhead of health services for the community as it is effective enough to assist the community in providing first aid with health service standards. Well-known health services should make Center for Public Health the primary health service for the community, but in reality many people prefer health services to private practice physicians or other health practitioners. This condition is based on the negative initial perception of the community on the Center for Public Health service, for example the assumption that the quality of the service is seemingly improbable, meaning that the health center is not sufficient enough to provide services to the community, whether viewed from the facilities and infrastructure or from medical personnel or budget used to support his daily activities. So a lot of services provided to the community is not in accordance with Standard Operating Procedure (SOP) that has been established. The undisciplined attitude of medical personnel in the health center of health services unit also becomes a problem. People are always treated poorly by medics who are considered arrogant, arguing that the limited supply of medicines at health center has caused many patients to buy drugs at pharmacies. Not only the things that have been disclosed above, more than that, there are still problems that arise in the scope of health centers, for example: Health Center work hours are very short just until 12.00 WIB and additional time overtime until 14.00 pm, limited local financial capacity, Health Center lacking the authority to take advantage of existing opportunities, Health Center not yet accustomed to manage their activities independently, and lack of employee welfare that affect the motivation in performing duties at Health Center.

Implementation of management is a crucial important in achieving the efficient and effective goals of the Health Center goals. It can be said also that the lack of knowledge of the Head of Health Center and the low discipline/work ethic of the staff, makes this element of management is not running. Of course this impedes performance. The facilities and infrastructure at the Health Center in Indonesia seem to be disregarded by the government on the grounds that geo- 
graphical areas are difficult to reach, so that the facilities and infrastructure in the Health Center are very limited, both in the form of medical devices and medicines. This happens as a result of the financial resources owned by the Health Center is limited so that the quality of Health Center Health services becomes low because it is not in accordance with the standard of health. Medical personnel: A very small number of medical personnel result in their inability to implement programs from the Health Office.

\subsection{Clean and Healthy Living Behavior (PHBS)}

Clean and healthy life behavior (PHBS) is an effort to provide a learning experience or create a condition for individuals, families, groups and communities, by opening lines of communication, providing information and educating, to improve knowledge, attitude and behavior through leadership (advocacy), social support and empowerment so that they can apply healthy ways of life in order to maintain, maintain and improve public health (Dinkes, 2006).

The purpose of PHBS is to increase the knowledge, awareness and willingness of the community to live healthy, as well as to increase the active role of the community, including the private sector and the business community, in order to realize optimal life (Dinkes, 2006).

In the household setting, the indicator of PHBS is (Dinkes, 2006):

1. Relief delivery by health personnel

2. Immunization and weighing

3. Family latrines

4. Clean water

5. Handling garbage

6. Nail hygiene

7. Family nutrition

8. Smoking habits and abuse of drugs

9. PMS / AIDS Information

10. JPKM / Health Fund / other Askes.

Environmental indicators by DHO (2006), in PHBS, include:

1. There are latrines, including their use and maintenance

2. There is clean water and utilization for health

3. There is a dumpster and its management

4. There is a sewerage and its management

5. There is ventilation

6. Density of occupants

7. Floor is not ground

PHBS in the workplace is an effort to empower workers to know, willing and able to practice PHBS and play an active role in realizing a healthy workplace. Implementation of PHBS in the workplace is necessary to maintain, maintain and maintain workers' health in order to remain healthy and productive (Dinkes, 2009). The benefits of PHBS in the workplace among the people around the workplace to be healthier and not easily sick, and the environment around the workplace to be cleaner, beautiful and healthy. Terms of healthy public places according to DHO (2009) are:

1. Eat nutritious foods

2. Perform physical activity every day

3. No smoking in the workplace

4. Hand wash with clean water and soap

5. Using clean water

6. Fighting larvae at work

7. Using latrines

8. Take out the garbage in its place

\subsection{Diarrheal diseases}

According to the World Health Organization (WHO), diarrheal disease is a disease characterized by changes in the shape and consistency of stools soft to melt and increased frequency of bowel movements more than usual, which is 3 times or more a day which may be accompanied by vomiting or bloody stools. The disease is most common in children under five, especially in the first 3 years of life, where a child may have 1-3 episodes of severe diarrhea (Simatupang, 2004).

In the Department of Child Health FKUI, diarrhea is defined as an abnormal bowel movement or a watery form of stool with more frequencies than usual. Neonatal diarrhea declared when the frequency of bowel movements for more than 4 times, while for infants older than 1 month and children, the frequency is more than 3 times (Simatupang, 2004).

According to WHO (2005) diarrhea can be classified to:

1. Acute diarrhea, which is diarrhea lasting less than 14 days.

2. Dysentery, which is diarrhea accompanied by blood.

3. Persistent diarrhea, ie diarrhea lasting more than 14 days.

4. Diarrhea accompanied by severe malnutrition (Simatupang, 2004).

According to Ahlquist and Camilleri (2005), diarrhea is divided into acute if it is less than 2 weeks, persistent if it lasts for 2-4 weeks, and chronic if it lasts more than 4 weeks. More than $90 \%$ of the causes of acute diarrhea are infectious agents and will be accompanied by vomiting, fever and abdominal pain. Another $10 \%$ is due to treatment, intoxication, ischemia and other conditions. In contrast to acute diarrhea, the cause of chronic diarrhea is commonly caused by non-infectious causes such as allergies and others.

Among the steps that can be done most important is to maintain personal hygiene well. This can be done by carrying out healthy behaviors, namely washing hands with soap after disposing of faeces and after defecation and also before preparing food to the child. Mothers should also train their children early on about handwashing behavior especially before eating and after playing. This can prevent the occurrence of transmission of germs that can cause diarrhea.

Based on many studies, affordability of the use of clean water facilities is essential to reduce the risk of diarrhea. Therefore, the public should ensure that the water used at home is completely clean and qualifies ie it has no color, smell and taste before being used for daily purposes.

1. Diarrhea Prevention Based on Dehydration Level (WHO, 2005)

a) Without Dehydration

In children under 2 years of age, oral solution may be 50 $100 \mathrm{ml} /$ times and for ages over 2 years is given the same solution with a dose of $100-200 \mathrm{ml} /$ diarrhea. For the avoidance of dehydration, mothers should raise the usual provision of drinks and food to their children. In addition it can also be given zinc (10-20mg/ day) as an additional food.

b) Light Dehydration

In this circumstance ORALIT ORALITE is required with Ringer Lactate or Ringer Acetate crystalloid solution with a complete formula containing glucose and electrolytes and administered as much as possible according to the child's abilities and the mother is encouraged to continue breastfeeding and still be handled by the family at home. According to WHO, ORS solution should contain $90 \mathrm{mEq} / \mathrm{L}$ 
sodium, $20 \mathrm{mEq} / \mathrm{L}$ potassium chloride and $111 \mathrm{mEq} / \mathrm{L}$ glucose .

c) Dehydration Medium

In these circumstances require more specific attention and oral administration should be performed by personnel at health facilities and patients should be monitored for 3-4 hours. If the patient has better conditions, the patient can be taken home to be treated at home with oralit. Dose of ORS for age less than 1 year, every of defecation is given $50-100 \mathrm{ml}$, for 3 hours first $300 \mathrm{ml}$. For children aged 1-4 years each of defecation is given $100-200 \mathrm{ml}$, for the first 3 hours $600 \mathrm{ml}$.

d) Severe dehydration

In this situation the patient will be given intravenous hydration solution with $100 \mathrm{ml} / \mathrm{kgBB} / 3-6$ hours. The dosage of fluid for age less than 1 year is $30 \mathrm{ml} / \mathrm{kgBB}$ for 1 hour and the next is given $75 \mathrm{ml} / \mathrm{kgBB}$ every 5 hours. The dosing of fluids for children $1-4$ years is $30 \mathrm{ml} / \mathrm{kgBB}$ for the first $1 / 2$ hour and so is given $70 \mathrm{ml} / \mathrm{kgBB}$ every $2 \frac{1}{2}$ hours.

d) Complications

The major complications of gastroenteritis are dehydration and cardiovascular problems due to severe hypovolemia. If the diarrhea is caused by Shigella, high fever and seizures may arise. Abscesses of the intestinal tract may also arise from the infection of shigella and salmonella especially in typhoid fever which can cause perforation of the intestinal tract. It is very dangerous and life threatening. Severe vomiting can cause aspiration and tears in the esophagus (Kliegman, Marcdante, Jenson, Behrman, 2006).

Theoretical framework used by the authors in this study consists of 3 (three) theories of H.L.Blum theory in Wibowo (2014); Lawrence Green's theory in Notoatmodjo (2003). Determinant factors of health and disease are increasingly evolving along with the great transition that occurs in an infection pattern that is more vulnerable to epidemic diseases that occur in both old and new cases. In addition, cases of non-communicable diseases show an increasing trend from year to year.

\section{Research Methods}

The type of research used in this study is analytic research that not only describes certain characteristics, but also analyzes and explains why or how it happens (Hermawan, 2006). This research was conducted in Palembang City selected area sub-division of Karang Jaya Sub-district Gandus. The study took place in May August 2016-June 2017. Population is a generalization area consisting of objects/subjects that have certain qualities and characteristics set by the researchers to be studied and then drawn conclusions (Sugiyono, 2009).

The population in this study is the entire community recorded in Karang Jaya as many as 325 people. Sampling technique in this study using simple random sampling. Random sampling was conducted on a certain cluster of areas considered to be representative of the population to be studied (Azwar and Prihartono, 2003). The sample of the study was 100 people affected by diarrhea in 2017 . The variables of this study are independent variables (Independent variable), ie community behavior (X1) and service quality (X2). The dependent variable in this research is the prevention of Diarrhea Disease (Y1). Method of data analysis used univariate analysis done to each variable from research result. By using the frequency distribution to know the description of the characteristics of respondents. Multivariate analysis using logistic regression.
Table 1. Distribution of Respondents by Education

\begin{tabular}{|c|c|c|c|}
\hline No & Education & Frekuensi & Percentage \\
\hline 1 & Eliminery School & 17 & 17.89 \\
\hline 2 & Junior High School & 31 & 32.63 \\
\hline 3 & Senior High School & 37 & 38.95 \\
\hline 4 & Tamat PT & 10 & 10.53 \\
\hline \multicolumn{2}{|c|}{ Jumlah } & 95 & 100 \\
\hline
\end{tabular}

Sources: Primary Data

\section{Result}

Respondents in this study were respondents who are diarrhea resident in Gandus District Health Center work area that is as much as 95 respondents, with the average age of respondents 30.29. Median age of respondents 29.00. Minimum age of respondents is 22 years and the maximum age of respondents is 43 years, and Standard Deviation (S.D) is 5,139 .

In Table 1. Known that the education of most of the respondents is high school graduation, which amounts to 37 people $(38.95 \%)$ and the least is graduated from university (PT) which is 10 people (10.53\%). The result of cross-tabulation of the availability of clean water facilities with the incidence of diarrhea in toddlers is known that among 63 respondents who did not have clean water facilities, there were 36 people $(57.14 \%)$ who had a child with a history of diarrhea and 27 people (42.9\%) with bales - it has no history of diarrhea. Among the 32 respondents who had clean water facilities, there were 7 people $(21.9 \%)$ with a history of diarrhea and 25 people $(78.1 \%)$. This is in accordance with the proposed by Slamet (2002: 95), that the source of drinking water is often a source of pollutants in water borne disease. Therefore drinking water sources must meet the requirements of localization and construction. Localization requirements require that drinking water sources be protected from contamination, so it is necessary to consider the distance of drinking water sources with latrines, waste excavation pits, excavation pits for waste water, and other pollutant sources. Clean water can be a contagious medium for various diseases carried by water if the facility is not sanitizer. Clean water facilities other than quantity, the quality must meet the prevailing standards, to prevent the occurrence and widespread disease of water congenital. However, clean water is often stored in areas where water is not clean or easily contaminated, then safe or healthy water will become dangerous again (Slamet, 2002: 111). One effort to minimize the risk of diarrheal diseases, namely the procurement and improvement of clean water facilities cleanliness so as to avoid contamination of disease-causing agents. In addition, the public must cook drinking water first to turn off the disease-causing agent contained in the clean water (Stefano, 2011).

The results of logistic regression analysis explain the factors that influence the occurrence of diarrhea is analyzed using Logistic Regression approach, where the dependent variable is qualitative data in the form of nominal data in dummy form. The dummy of this dependent variable is yes (buy) or not (do not buy). The method of dummy code is given by using the category stated with the number 1 called the included group for diarrhea category and assigned a value of 0 (zero) called the excluded group for the non diarrhea category. Factors affecting the incidence of diarrhea (Y) are PHBS (X1) and quality of health care (X2). The results of logistic 
Table 2 Logistic Regression Analysis

\begin{tabular}{|l|c|c|c|c|c|c|c|}
\hline \multicolumn{1}{|c|}{ Variables } & B & SE & Wald & Sig. & Exp (B) & \multicolumn{2}{c|}{ 95\% C.I. for EXP(B) } \\
\cline { 3 - 8 } & & & & & & Lower & Upper \\
\hline PHBS (X1) & -0.274 & 0.367 & 5.558 & 0.045 & 0.76 & 0,370 & 1.561 \\
\hline $\begin{array}{l}\text { Quality Of Health Care } \\
\text { X2) }\end{array}$ & -0.469 & 0.357 & 5.723 & 0.009 & 1.598 & 0.794 & 3.217 \\
\hline Constanta & 0.722 & 0.282 & 6.566 & 0.01 & 2.059 & & \\
\hline
\end{tabular}

Table 3. Omnibus Tests of Model Coefficients

\begin{tabular}{|l|l|c|c|c|}
\hline & & Chi-square & Df & Sig \\
\hline Step 1 & Step & 12.244 & 4 & 0 \\
\hline & Block & 12.244 & 4 & 0 \\
\hline & Model & 12.244 & 4 & 0 \\
\hline
\end{tabular}

regression analysis of factors considered to affect the incidence of diarrhea are presented in Table 2 below.

The calculation result of logistic regression analysis of factors that influence the occurrence of diarrhea obtained by equation as follows:

$$
\mathrm{Y}=2.059-0.904 \mathrm{X}_{1}-0.903
$$

To test that the model (which has included its independent variable) is fit with the data, it should be seen from:

Based on the above table, the value of $\chi 2$-count is 12,244 with degrees of freedom $=4$, whereas the value of $\chi^{2}$-table with degrees of freedom $=6$ is 9.48, means $\chi^{2}$-count $>\chi^{2}$-table (12.244>9.48). Thus the model is fit with the data and analysis can be continued. Assessing the whole model shows a better logistic model or vice versa between logistic models on Block number $=0$ and Block number $=1$. This is based on the Log-2 Log Value. According to Appendix 6, we get the Log-2 value of Block Number $=0$ for 74.213 while Block number $=1$ is 74.137 . This decrease shows a better logistic model, meaning the logistics model on Block number $=1$ is better than Block number $=0$.

The new model determination is better than the initial model indicated by the Log Likelihood value drop- 2 from the initial model. Cox \& Snell R Square value is a measure that tries to mimic $\mathrm{R} 2$ size in multiple regression based on likelihood estimation technique with maximum value less than 1 (one), while for Nagelkerke R2 value can be equated with Adjusted R2 value in multiple regression. The results of iteration history and model summary are presented in the following table.

Based on Table 3 shows that the value of Nagelkerke R Square obtained value of 0.437 which means that the variability of the dependent variable $\mathrm{Y}$ (factors affecting the occurrence of diarrhea) which can be explained by the variability of the independent variables (product, health service quality, message format and message source) $43.7 \%$. The Likelihood Log -2 values is 74.137 whereas -2 Log Likelihoods initially of $45.1 \%$, it means that the Log-Likelihood value decrease and Log-Likelihood Log-2 decrease indicates that the new model is better, so the analysis can proceed.

To see that the model made is good and fit with the data then seen on the statistical value of Hosmer and Lemeshow Test Goodness-of-fit. The Goodness-of-fit Hosmer and Lemeshow Test is pre-
Table 3 Iteration History and Model Summary

\begin{tabular}{|c|c|c|c|}
\hline Step & -2 Log Likelihood & $\begin{array}{c}\text { Cox \& Snell R } \\
\text { Square }\end{array}$ & $\begin{array}{c}\text { Nagelkerke R } \\
\text { Square }\end{array}$ \\
\hline 1 & $74.137 \mathrm{a}$ & 0.437 & 0.451 \\
\hline
\end{tabular}

Table 4 Hosmer and Lemeshow Test Goodness-of-fit

\begin{tabular}{|c|c|c|c|}
\hline Step & Chi-square & df & Sig. \\
\hline 1 & 9.069 & 8 & 0.336 \\
\hline
\end{tabular}

sented in Table 4.

Based on Table 4, the value of Hosmer and Lemeshow Test Goodness-of-fit is 9.069 with significance value 0.336 (p> $0.05)$, so it can be concluded that the model is acceptable. The size of LR statistics in logistic model is similar to F test on multiple linear regressions. The $\mathrm{F}$ value as shown in 6 which in the logistic model is called LR statistic of 12.2244 with the level of significance equal to zero then the first hypothesis is proved. This shows that simultaneously all advertising variables have a significant effect on Canon camera purchase decision. The waldz test is used to partially test the effect. Hypothesis test results are described as follows.

a. Coefficient of PHBS with odds ratio-0.760 (1,561-0,370) with significance of 0.045 less than the 0.05 significance level $(\alpha)$. This means that hypothesis one (H1) is accepted if the variable quality of health service, constant then every increase PHBS effect on the occurrence of diarrhea. The better PHBS will decrease the incidence of diarrhea.

b. The coefficient of health care quality with an odds ratio of 1.598 $(3,217-0,74)$ with significance of 0.009 less than the 0.05 significance level $(\alpha)$. This means that hypothesis two (H2) is accepted if the variable PHBS, constant then the quality of health services affect the occurrence of diarrhea. The better quality of health care will reduce the incidence of diarrhea.

Based on the value of Cox and Snell R square of 0.290 or $29 \%$ and Nagelkerke R Square of 0.410 or $41 \%$ means PHBS and the quality of health services to the incidence of diarrhea by $41 \%$ while the rest influenced by outside the research variables of $69 \%$.

\section{Disscusion}

\subsection{Effect of PHBS on Diarrhea Occurrence}

The behavior of healthy living is related to the degree of health and 
the level of disease transmission in the community. Poor environmental sanitation also affects the occurrence of diarrhea. Interactions between agents, diseases and host and environmental factors that cause disease need to be taken into account in the prevention of diarrhea. The role of environmental factors (water, excreta, food, flies and other insects), entire--bacteria, intestinal parasite, viruses, fungi and some chemicals have been classically proven in various epidemiological investigations as causes of diarrheal disease Environmental health in Indonesia is still a major problem in efforts to improve public health status. These environmental health concerns include the lack of clean drinking water supply and health requirements, lack of healthy sewage disposal, generally unhealthy housing conditions, hygiene and sanitation of incomplete food, the number of disease factors, the lack of hygiene and sanitation of the industry intensively, lack of monitoring and prevention efforts against environmental pollution, waste disposal in poor residential areas.

The result of data analysis showed that PHBS had an effect on the occurrence of diarrhea. If PHBS community is better than the incidence of diarrhea will be suppressed or decreased because a pole healthy life has been applied in society. PHBS in this study with attitude, actions and public behavior about drinking water, environment, cleanliness, waste management and the surrounding environment.

The main drinking water source is one of the most important sanitation facilities related to the occurrence of diarrhea. Some infectious germs that cause diarrhea are transmitted through the oral fecal pathway. They can be transmitted by inserting into mouths, fluids or contaminated articles with feces, such as drinking water, fingers, and food prepared in pots that are washed with polluted water (Ministry of Health of the Republic of Indonesia, 2000). According to Slamet (2002) various sources of drinking water include: 24 a) Surface water is water that is on the ground surface. For example river water, swamp water and lakes. b) Depth-dependent soil water may be called shallow groundwater or deep ground water. Water in soil is water obtained by collecting water on deep soil layers. For example water wells, water from springs. c) Space air is water that comes from the atmosphere, like rain and snow. According to the Ministry of Health of the Republic of Indonesia (2000), things to consider in the provision of clean water are: Taking water from a clean water source. b) Take and store water in a clean and enclosed place and use a special scoop to collect water. c) Maintain or maintain water sources from pollution by animals, children, and sources of contamination. The distance between drinking water sources and sources of sewage such as septic tanks, landfills and wastewater must be more than 10 meters. d) Using boiled water. e) Washing all cooking utensils and eating with clean and sufficient water.

Based on the results of research in the area of Karang Jaya against the incidence of Diarrhea, that more respondents who diarrhea. It shows that people with diarrhea are still low. Due to the use of clean water, the community has no concern for the use of clean water in daily life (such as drinking, washing vegetables and washing other foods). Communities accessible by clean water provision have a lower risk of diarrhea than people who do not get clean water. As stated in the Diarrhea Diagnostic Guidelines (MOH RI, 2003) that Diarrhea is one of the most environmentally-based diseases, the dominant factors allow the occurrence of Diarrhea such as clean water facilities, and the use of healthy latrines and fecal matter disposal will interact with human behavior (individual/family members/community). If the factor is not healthy due to contaminated germs. Diarrhea and accumulate with unhealthy human behavior, i.e. through food and drink or do not wash hands with clean water will cause diarrhea. The results of this study are consistent with Gaffar's (2012) research, Elfi Rahmawati et al (2008), Bui Viet Hung (2006) and Juan Correa et. al (2013) indicating that PHBS has an effect on the occurrence of diarrhea.

\subsection{Quality of Health Services}

Good health care is a necessity for everyone. Everyone wants to be served and get the same position in health service. In the 1945 Constitution, Article 28 and Article 34 states that the state guarantees every citizen to live a healthy life, health, and health service in Indonesia, but there is often a dichotomy in the effort of health service, capable societies while the less well-off are not treated equally and proportionally. Health services are one of the basic rights of the community whose provision must be administered by the government.

The results of data analysis show that health services have an effect on the occurrence of diarrhea. If community satisfaction on health services is better then the incidence of diarrhea will be suppressed or decreased because apola healthy life has been applied in the community. Public satisfaction with health services in this study was measured by those obtained in improving health status.

One of the health facilities that many people use is Center for Public Health. As the spearhead of health services and development in Indonesia, Center for Public Health need to get attention especially related to health service quality of Center for Public Health so in this case Center for Public Health especially at Center for Public Health equipped with inpatient unit is demanded to always increase the professionalism of its employees and improve its facilities / provide satisfaction to the community of health-care users. In the incidence of diarrhea, Center for Public Health services in Gandus sub-district can affect the incidence of diarrhea in this region.

Azrul Azwar (1988: 40) defines health services as any effort that is carried out independently or jointly within an organization to maintain and improve health, prevent and treat disease and restore the health of individuals, groups, and or society. Azrul Azwar (1994: 21) states that the quality of health services is pointing to the level of perfection of the appearance of health services that can satisfy every user of health services 6 in accordance with the level of satisfaction of the average population, the procedure of implementation in accordance with standards and professional codes of ethics that has been set.

\section{Conslusions and Recomendations}

The coefficient of PHBS with odds ratio-0.760 (1.561-0.370) with a significance of 0.045 less than the 0.05 significance level $(\alpha)$. This means that hypothesis one (H1) is accepted if the variable quality of health service, constant then every increase PHBS effect on the occurrence of diarrhea. The better PHBS will decrease the incidence of diarrhea. Coefficient of health service quality with odds ratio $1.598(3.217-0.74)$ with significance equal to 0.009 less than level of significance $(\alpha) 0.05$. This means that hypothesis two $(\mathrm{H} 2)$ is accepted if the variable PHBS, constant then the quality of health services affect the occurrence of diarrhea. The better quality of health care will reduce the incidence of diarrhea.

Suggestions that can be submitted in this study among others:

a. Maintain environmental conditions such as taking into account the conditions of household SPAL to be kept clean, keeping the yard of the house, the cleanliness of the sewerage, the use of latrines, the management of garbage by dis- 
posing of waste in place, not defecating or disposing of baby diapers or pampers in any place to prevent the occurrence of transmission of infectious diseases, especially diarrhea.

b. Doing the habit of washing hands with soap well and correctly, store and cook food well to be protected from pollution and pay attention to the use of clean water sources.

c. Diarrhea is still one of the major public health problems, because of the high rate of morbidity and mortality. The main cause of the incidence of diarrhea associated with healthy life style that exists in everyday life. Rehydration efforts using oral rehydration fluids are the only recommended therapeutic approach. The replacement of fluids and electrolytes is an important element in the treatment of acute diarrhea. Failure due to diarrhea is caused due to dehydration is too late handling. Another thing to note is the provision of adequate food or nutrition during diarrhea and treat comorbidities

\section{References}

Adisasmito W. 2007. Faktor Risiko Diare Pada Bayi dan Balita di Indonesia: Systematic Review Penelitian Akademik Bidang Kesehatan Masyarakat. Makara Kesehatan.

Anwar, 1997. Sanitasi Makanan Dan Minuman Pada Institusi Pendidikan Tenaga Sanitasi, Pusat Pendidikan Tenaga Sanitasi, Pusat pendidikan Tenaga Kesehatan Depkes RI. Jakarta

Bannister B, Gillespie, S. Jones, Jane. 2006. Infection: Microbiology and Management.3rd ed. USA: Blackwell Publishing Ltd
Cairncross S, Valdmanis, 2006. V. Water Supply, Sanitation and Hygiene Promotion. In: Dean T Jamison ea, editor. Disease Control Priorities in Developing Countries.2nd edition ed. Washington (DC): World Bank. p. 771-92.

Chang, Ju Young. 2008. Decreased Diversity of the Fecal Microbiome in Recurrent Clostridium difficile-Associated Diarrhea. J Infect Dis., 197(3): 435-438

Glanz K, Rimer, B.K and Viswanath, K. Health. 2008. Behavior and health education: theory, research, and practice. 4th ed ed. San Francisco: Jossey-Bass; 2008. p. 45-65, 189-207 and 407-30

Glanz K, Rimer, B.K and Viswanath, K. Social Cognitive Theory. In: Alfred L.McAlister CLPe, Guy S. Parcel, editor. Health Behavior And Health Education Theory, Research and Practice. San Francisco: Jossey-Bass; 2008. p. 170-88.

Gordis L. 2000. Case Control and Cross Sectional Studies in Epidemiology 2nd Ed ed.Philadelphia: W.B Saunders Company; p. 140-56.

Green L. 2000. Health Promotion Planning, An educational and environment approach. second ed. london: Mayfield Publishing company.

Nelly, Zavaleta. 2007. Efficacy of Rice-based Oral Rehydration Solution Containing Recom- binant Human Lactoferrin and Lysozyme in Peruvian Children With Acute Diarrhea. Journal of Pediatric Gastroenterology \& Nu- trition, 44(2): 258-264

Slamet, Juli Soemirat. 2002, Kesehatan Lingkungan, Yogyakarta: Gadjah Mada University Press

Stefano, Guandalini. 2011. Probiotics for Prevention and Treatment of Diarrhea. Journal of Clini- cal Gastroenterology, 45(2): S149-S153 